\title{
Experimental and Computational Sonic Boom Assessment of Boeing N+2 Low Boom Models
}

Fundamental Aeronautics Program High Speed Project

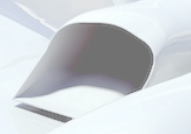

Don Durston

Alaa Elmiligui

Susan Cliff

Courtney Winski

Melissa Carter

Eric Walker
Ames Research Center Langley Research Center Ames Research Center Langley Research Center Langley Research Center Langley Research Center

32nd AIAA Applied Aerodynamics Conference

Aviation 2014 - Atlanta, Georgia 


\section{Outline}

- N+2 NRA Studies

- Study Goals and Objectives

- Boeing Full-Scale QEVC

- Wind Tunnel Tests

- Facilities, Models

- Test Techniques

- Selected Results

- Computational Tools

- Experiment / CFD Comparisons

- AS2

- Boom Models

- Performance Model

- Conclusions

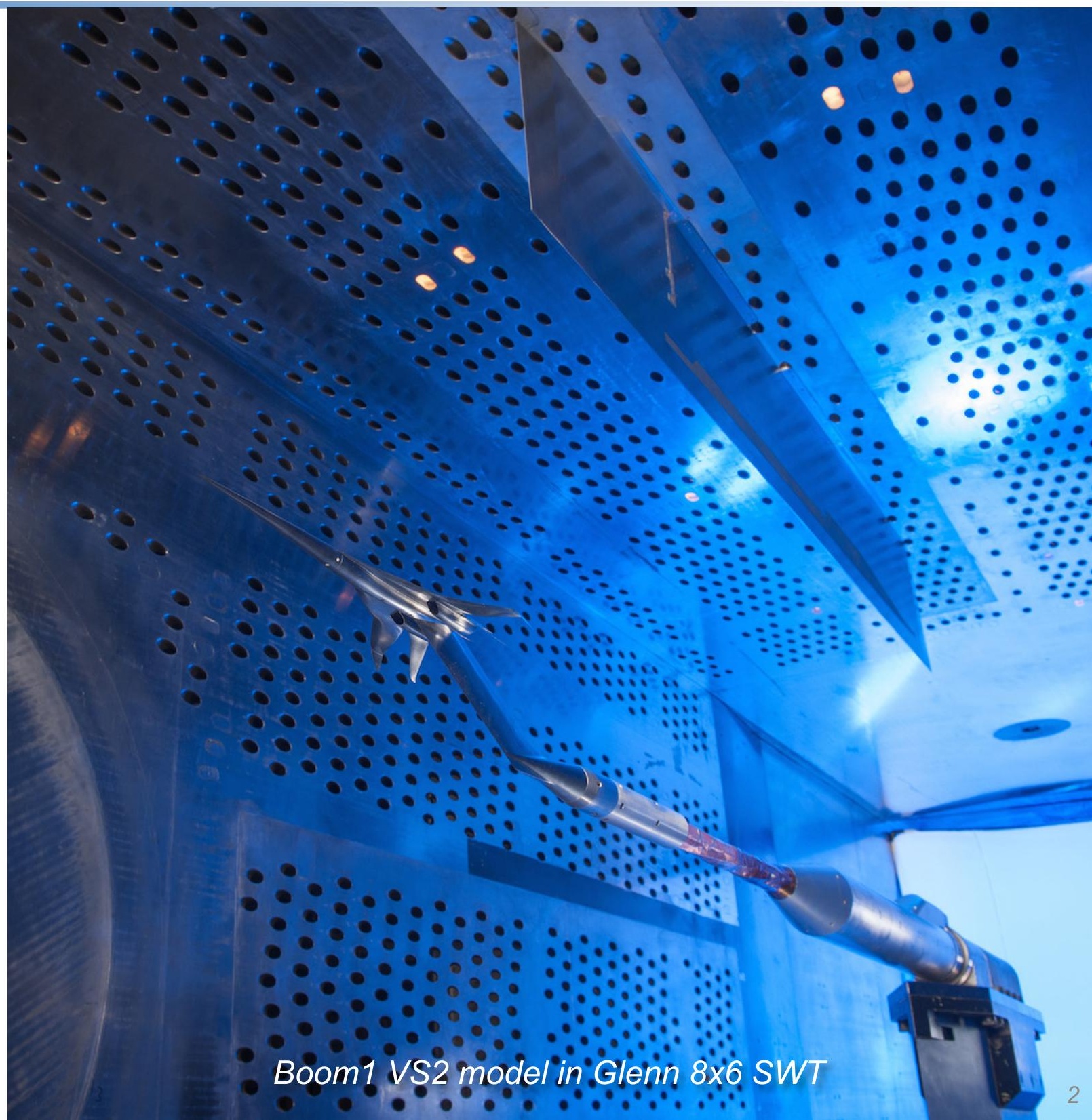




\section{N+2 NRA Studies}

- 3-year, 2-phase study contracts with Boeing and Lockheed-Martin

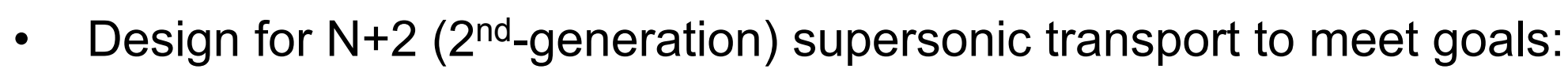

\begin{tabular}{|c|c|}
\hline \multicolumn{2}{|c|}{ Environmental Goals } \\
\hline Sonic Boom & 85 PLdB \\
\hline Airport Noise (cumulative below stage 3 ) & 10-20 EPNdB \\
\hline Cruise Emissions & $<10$ EIN Ox \\
\hline \multicolumn{2}{|c|}{ Performance Goals } \\
\hline Cruise Speed & Mach 1.6-1.8 low boom flight \\
\hline Range & $4000 \mathrm{~nm}$ \\
\hline Passengers & $35-70$ \\
\hline Fuel Efficiency (px-nm per lb of fuel) & 3.0 \\
\hline
\end{tabular}

- Phase I: Design for low boom and aerodynamic efficiency

- Phase II: Nacelle/airframe integration, inlet performance and effects on boom 


\section{Wind Tunnel Tests}

- Ames 9x7 and Glenn 8x6 Supersonic Wind Tunnels

- 14" RF1 pressure rail and 2" flat-top pressure rail

- Mostly Mach 1.6 and 1.8

- Performance model shown here, plus AS2 and Boom models (next page)

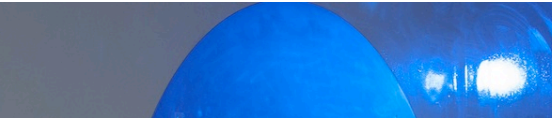

14-in. RF1 Pressure Rail

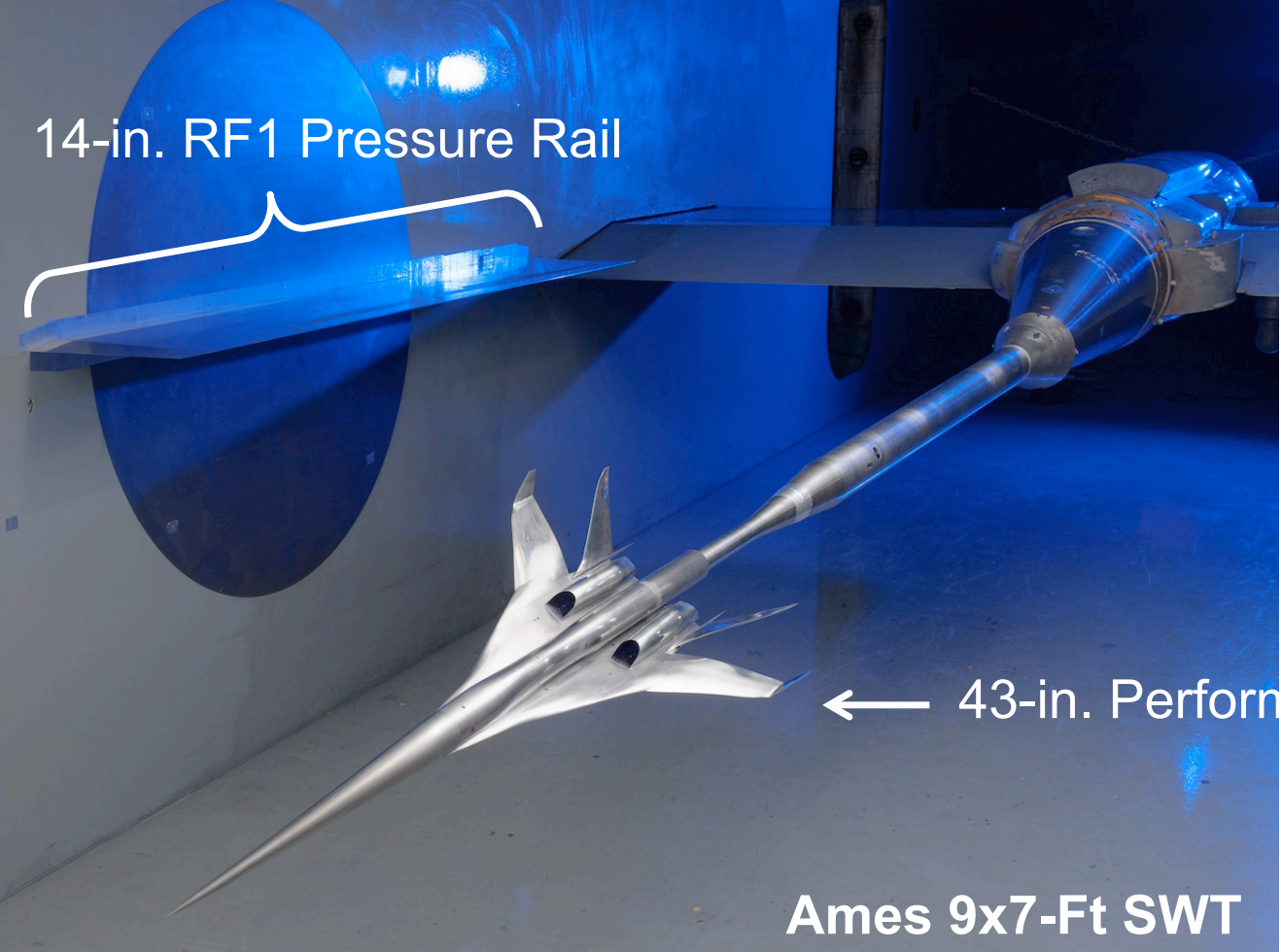

Glenn 8x6-Ft SWT 


\section{Pressure Rail Test Technique}

- Pressure rail on wall has 420 orifices to capture entire model signature at once

- Reference run taken with model shocks off rail (or at least downstream of where model shocks will be)

- Data run taken with model shocks on rail

- Model signature is difference between reference and data runs

- $X$ or $Z$ sweeps conducted to acquire signatures in different regions of tunnel flow

- Sweeps allow for averaging out tunnel spatial flow variations

- Temporal averaging also done with appropriate sampling durations
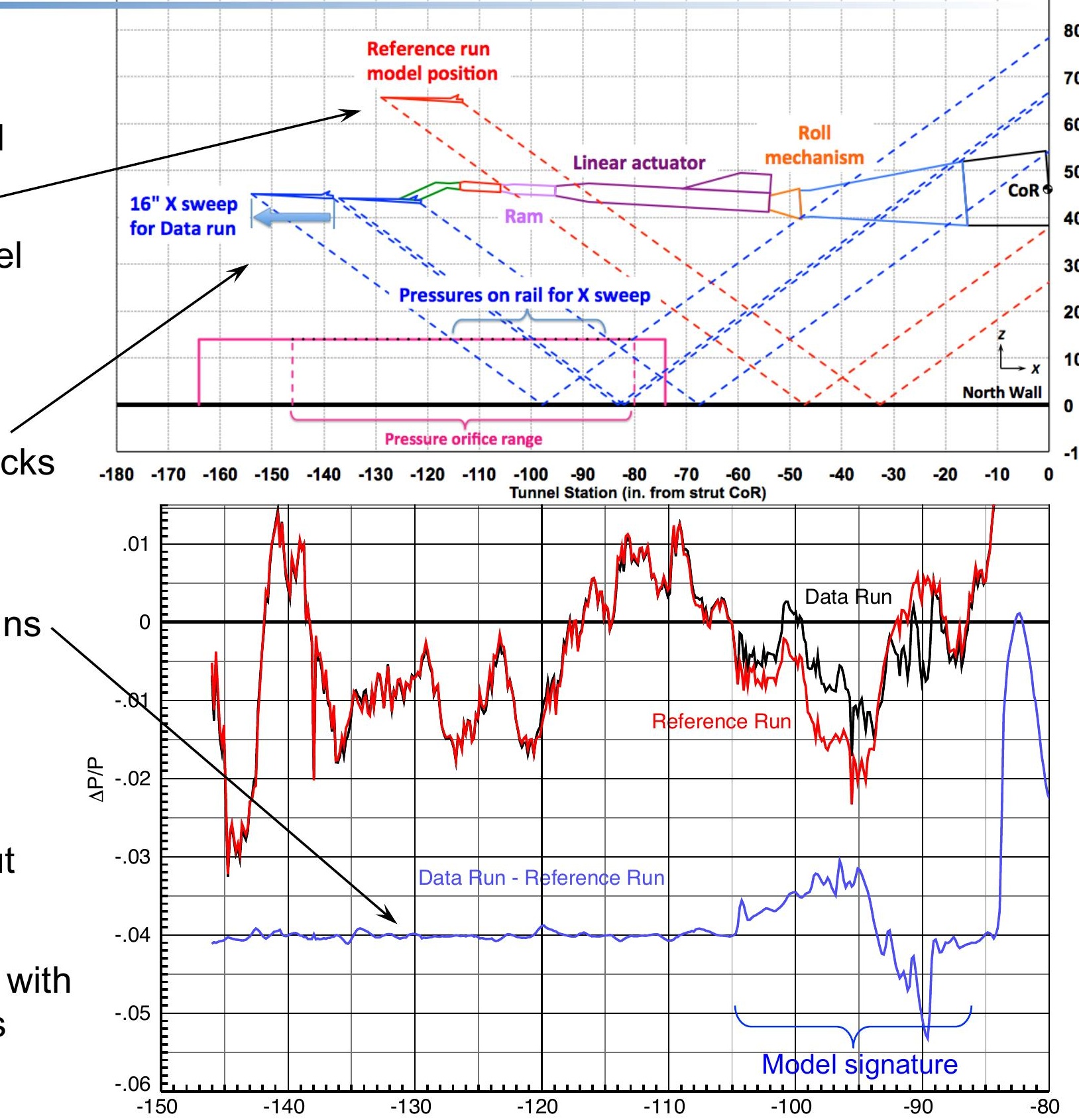


\section{Spatial Averaging of Model Signatures}

- Example: 26 signatures acquired with ram extension from 8" to 24 " (0.63" spacing)

- Distortions due to tunnel flow spatial variations and model vibrations are evident in individual signatures, but averaging reduces these effects
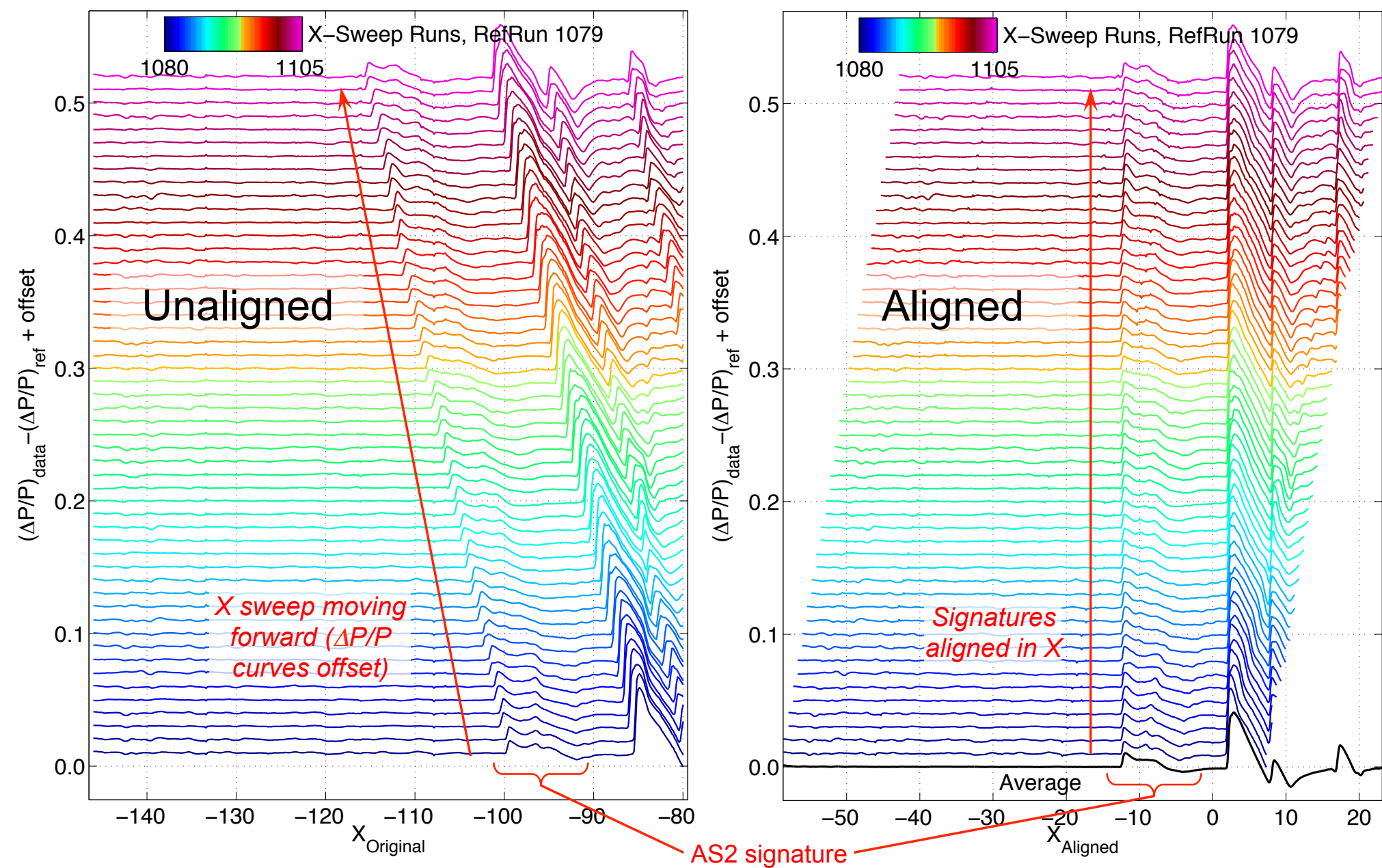

AS2 model

$X$ sweep in 9x7 WT,

Mach 1.6 


\section{Shock Wave Imaging}

- Facility-generated shock waves often as strong or stronger than model shocks being measured

- Reference runs and spatial averaging minimize effects of facility shocks but cannot eliminate these effects
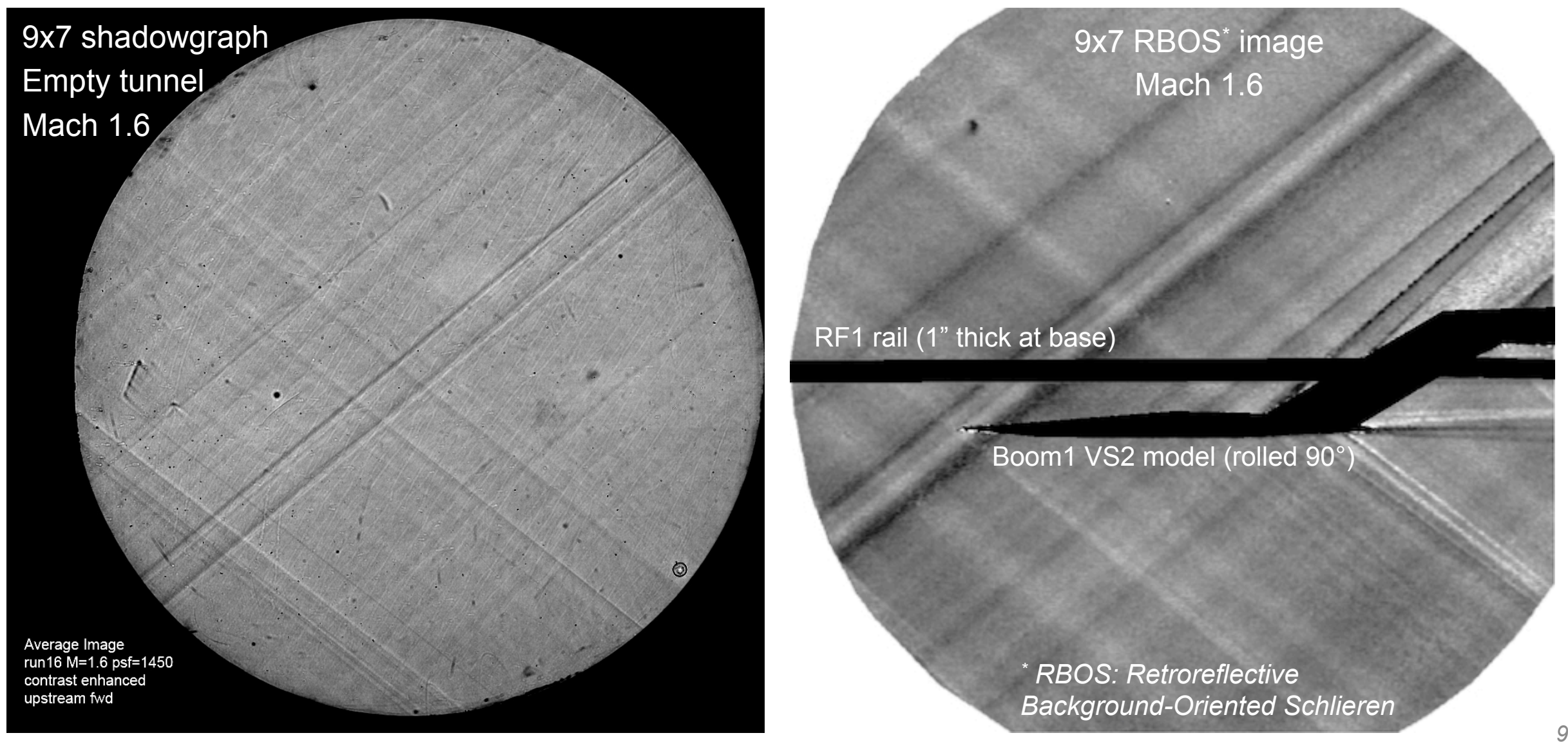


\section{Repeatability of Experimental Data}

- AS2 and Boom1 VS2 repeat runs show excellent repeatability

- $X$ and $Z$ sweeps give similar results

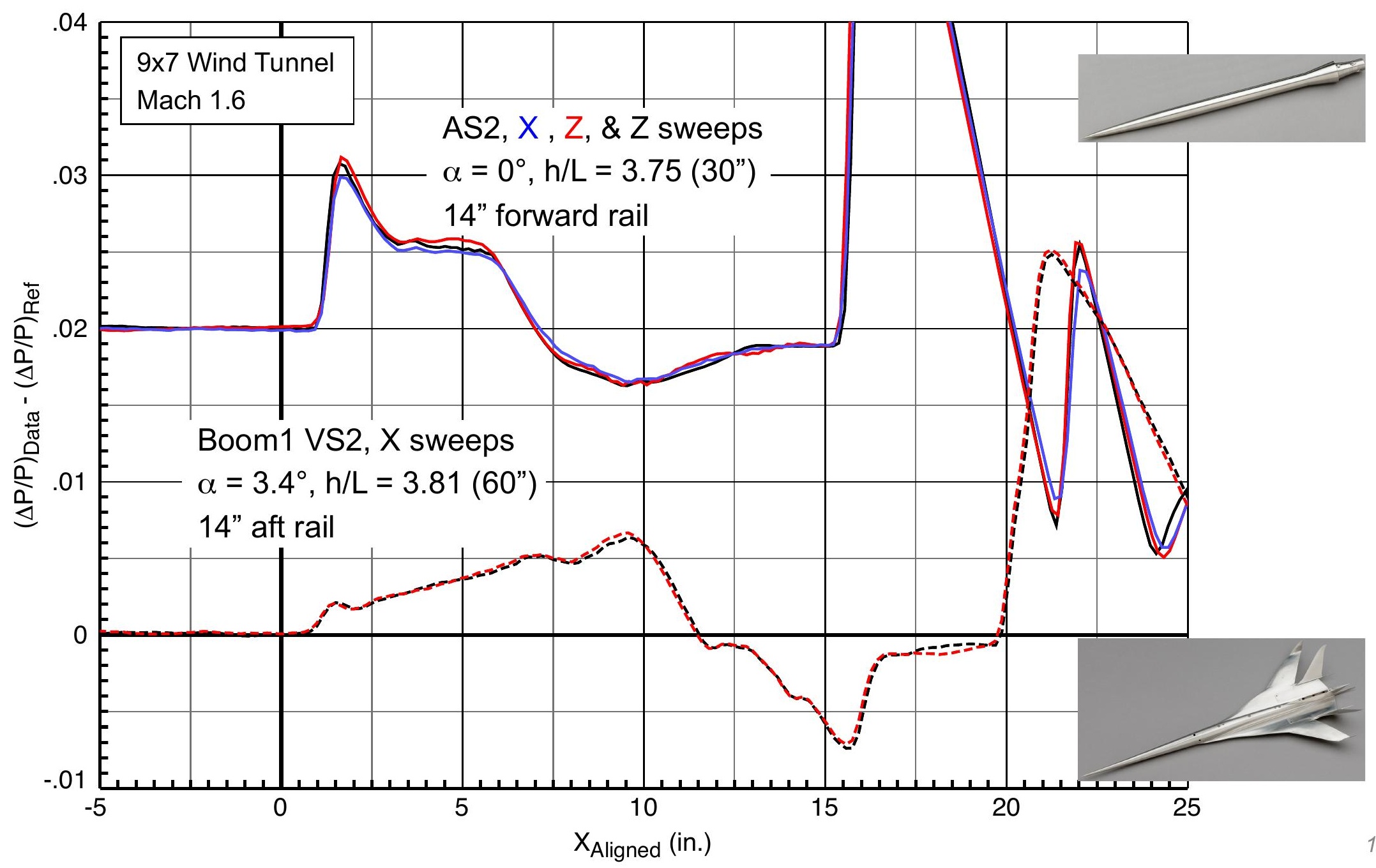




\section{Effect of Model Height, Boom1 VS2}

- Increased height causes rounding of signatures due to aging

- Overall pressure levels decrease with height

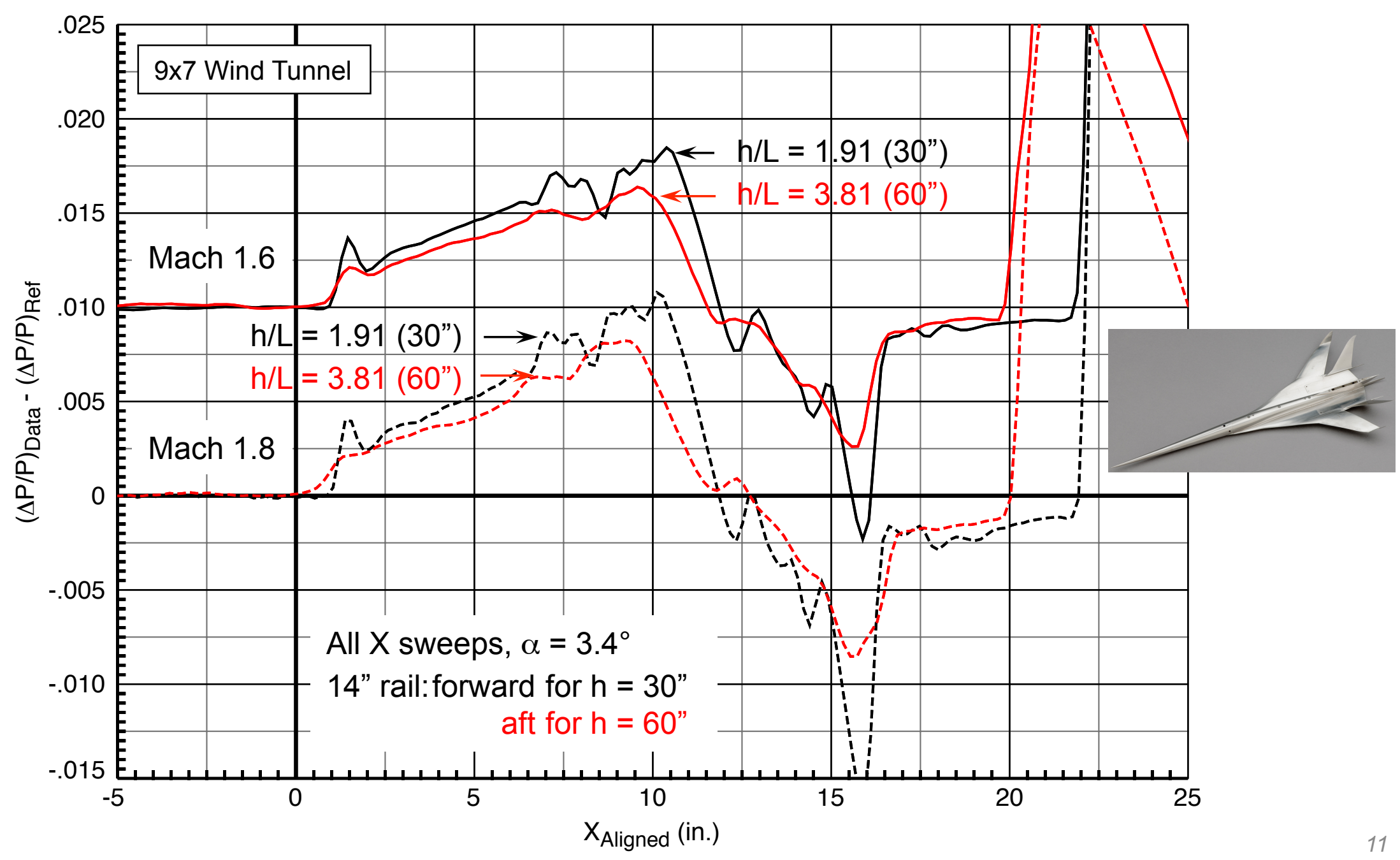




\section{Mounting Strut Effects, Boom Models}

- VS2,3,4 struts, Mach $1.6 \& 1.8,14$ " aft rail, height $=60 "$

- VS2 \& VS3 more similar to each other than to VS4, but VS3 \& 4 pressures more similar at Mach 1.6

- Greater differences between VS3 \& 4 exist at Mach 1.8, though angle-of-attack differences could account for part of this

- VS4 blade shock overtakes aft end of model signature at both Mach numbers

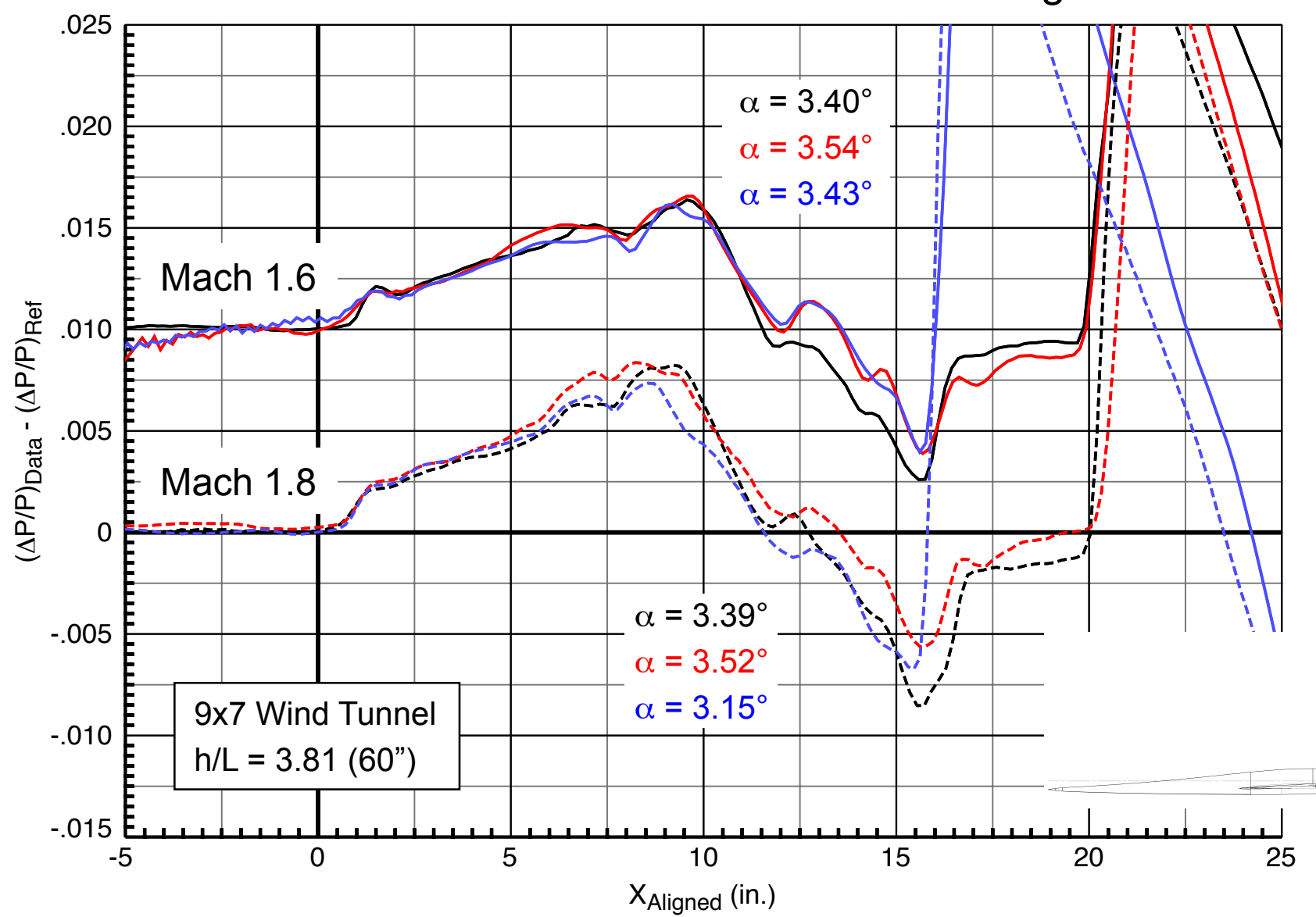

Boom1 VS2

Boom3 VS3

Boom3 VS4

Xligned (in.) 


\section{Computational Methods}

Results from 3 codes presented here:

- Cart3D

- Fast, inviscid, unstructured-mesh analysis package for conceptual and preliminary aerodynamic design

- Used with Adjoint Error Optimization (AERO) module

- USM3D

- Tetrahedral cell-centered, finite volume Euler and Navier-Stokes (N-S) method

- Run both inviscid and viscous (laminar, and turbulent with Spalart-Allmaras turbulence model) for this study

- OVERFLOW

- OVERset structured grid FLOW solver used by Boeing for present results

- Inviscid and turbulent with Spalart-Allmaras turbulence model 


\section{AS2 Grid and Pressure Contours}

- Cart3D adjoint-adapted grid and isobars in symmetry plane

- Sensor lines shown at heights of 30" and 60" for extracting pressure signatures

- Mach 1.6, $\alpha=0^{\circ}$
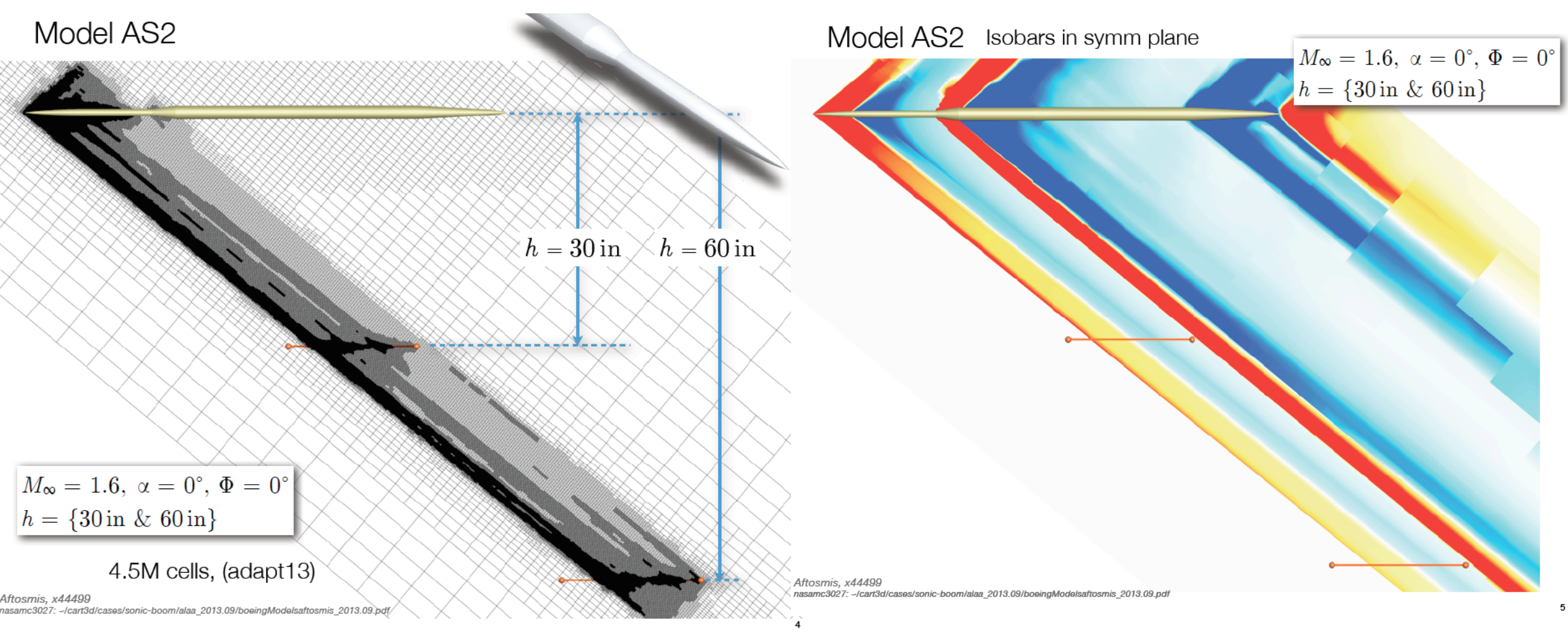


\section{AS2 Experiment / CFD Comparisons}

- Flat region aft of nose shock predicted well

- All CFD codes overpredict nose shock relative to experiment

- Shock in WT data may be rounded due to flow irregularities

- Viscous solutions not necessarily better than inviscid

- All CFD codes predict lower pressures in main expansion than experiment

- Similar differences found for other bodies of revolution tested (not shown here)

- Error was thought to be related to impingement of rail LE shock on aft part of model, but that was found to not be a factor

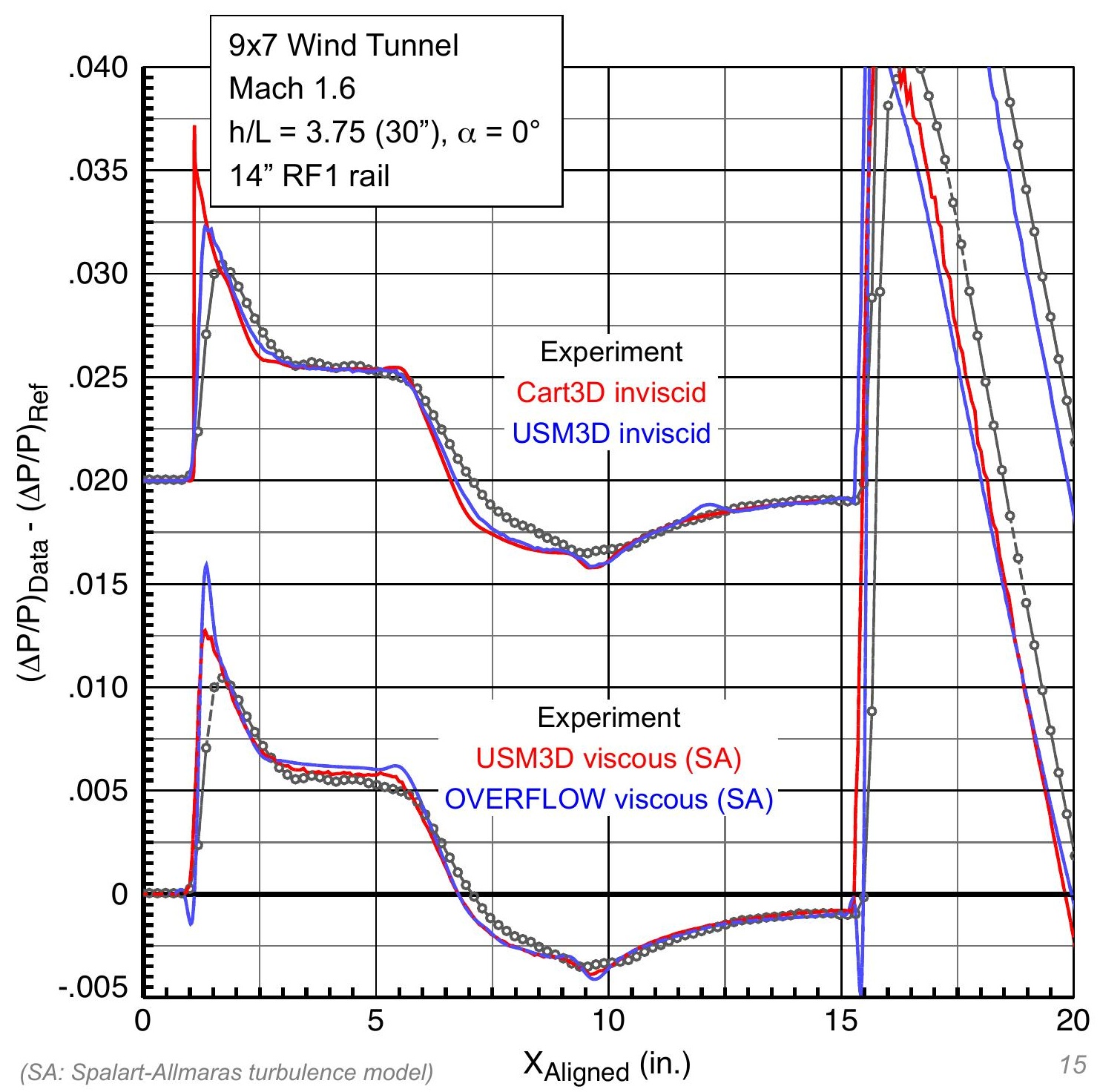




\section{Boom1 VS2 Pressure Contours}

- Surface pressure contours computed by USM3D with laminar boundary layers

- Mach 1.6, $\alpha=3.4^{\circ}$

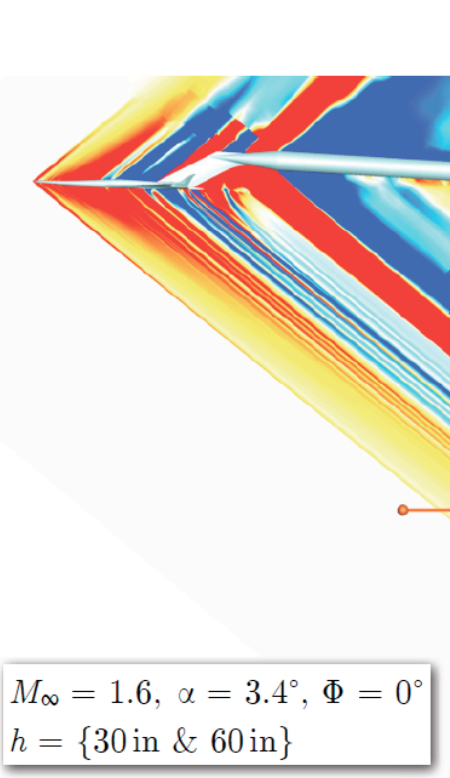

Isobars in symm. plane

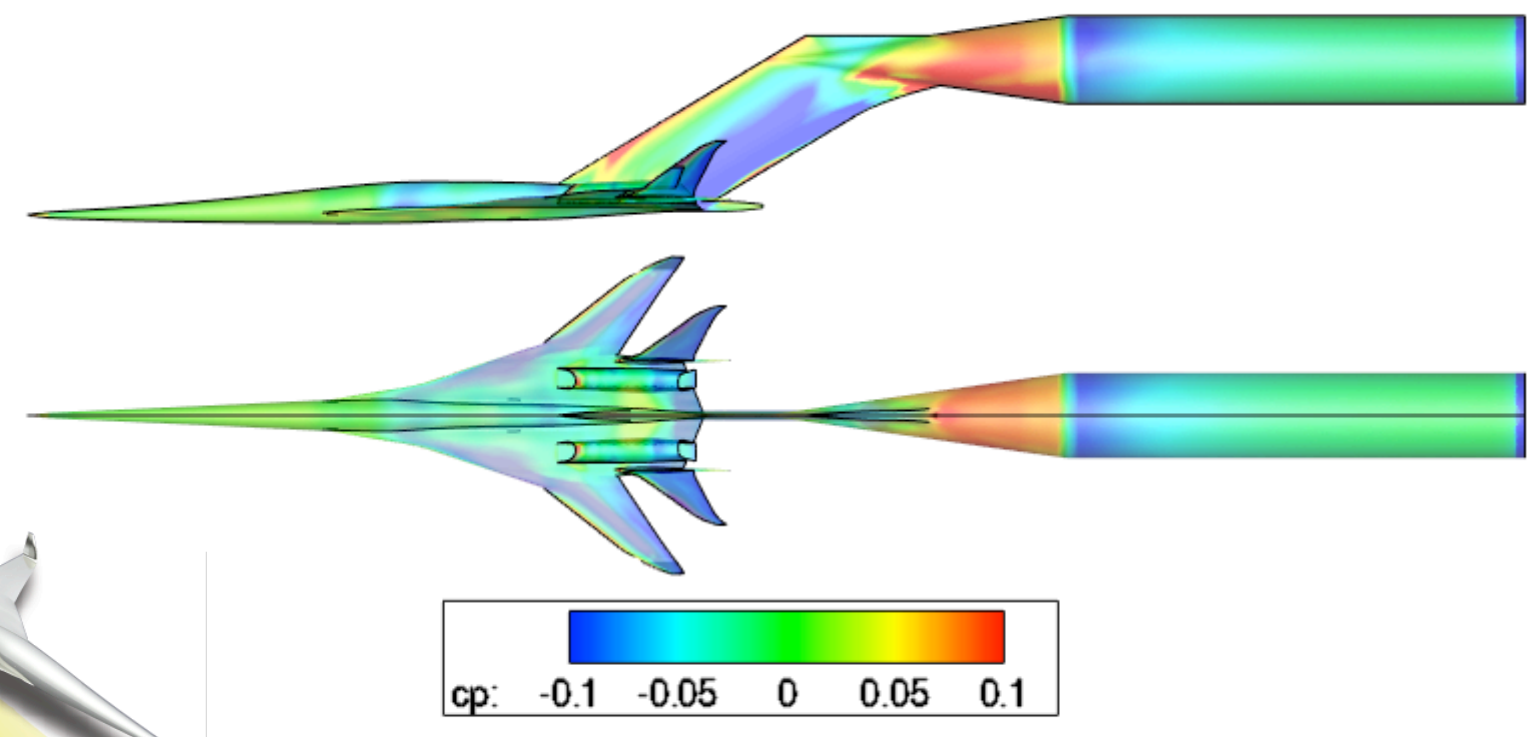

- Symmetry plane pressure contours computed by Cart3D

- Mach 1.6, $\alpha=3.4^{\circ}$ 


\section{Boom1 VS2 Experiment / CFD Comparisons}

- Inviscid shock peaks are overpredicted relative to viscous

- USM3D laminar prediction matches exp. data better than turbulent prediction from OVERFLOW

- Effects of model height well-captured by predictions

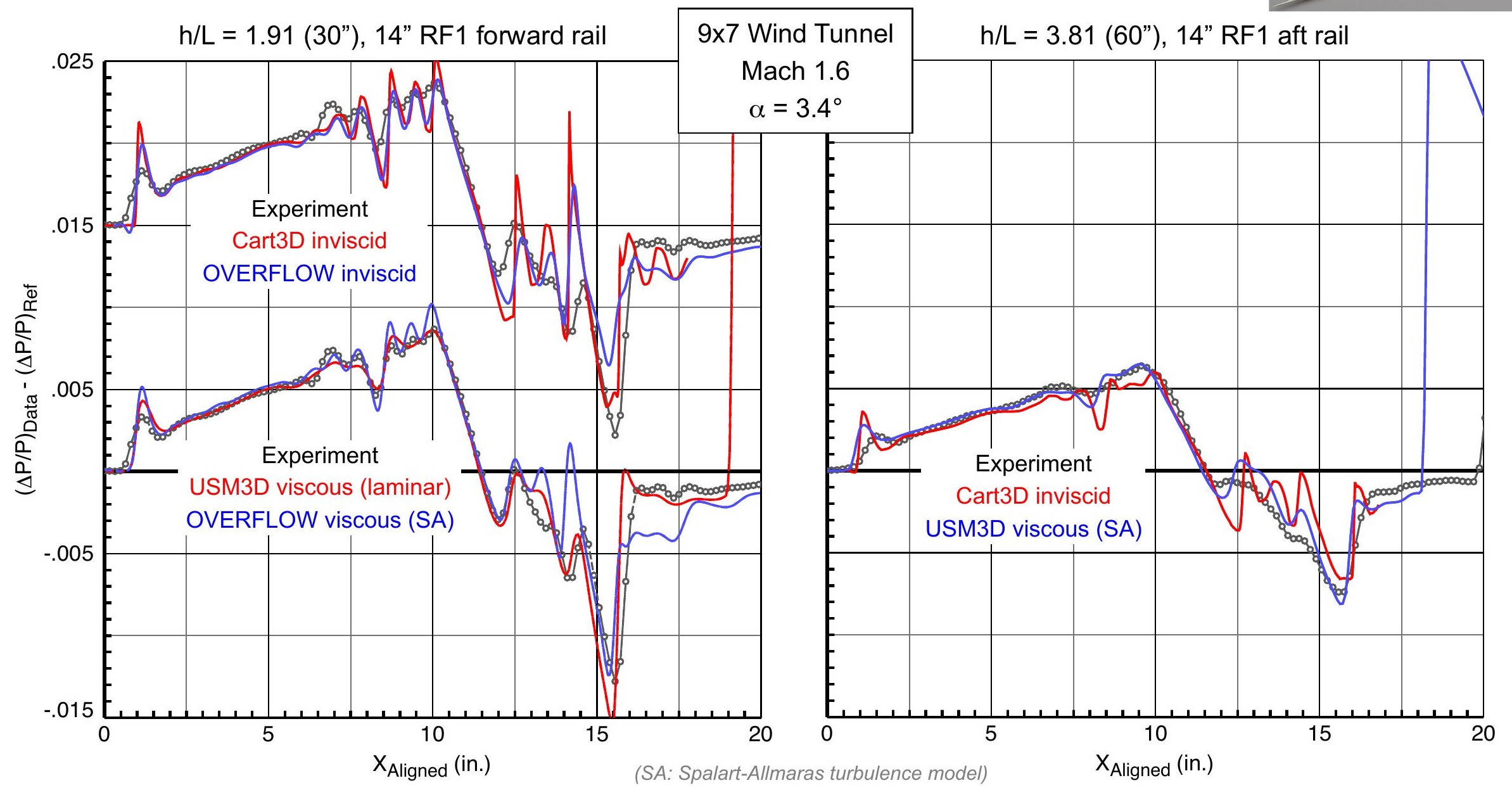




\section{Boom3 VS3 Pressure Contours}

- Surface pressures and symmetry plane flow field pressures computed by USM3D with laminar boundary layers

- Mach 1.6, $\alpha=3.1^{\circ}$
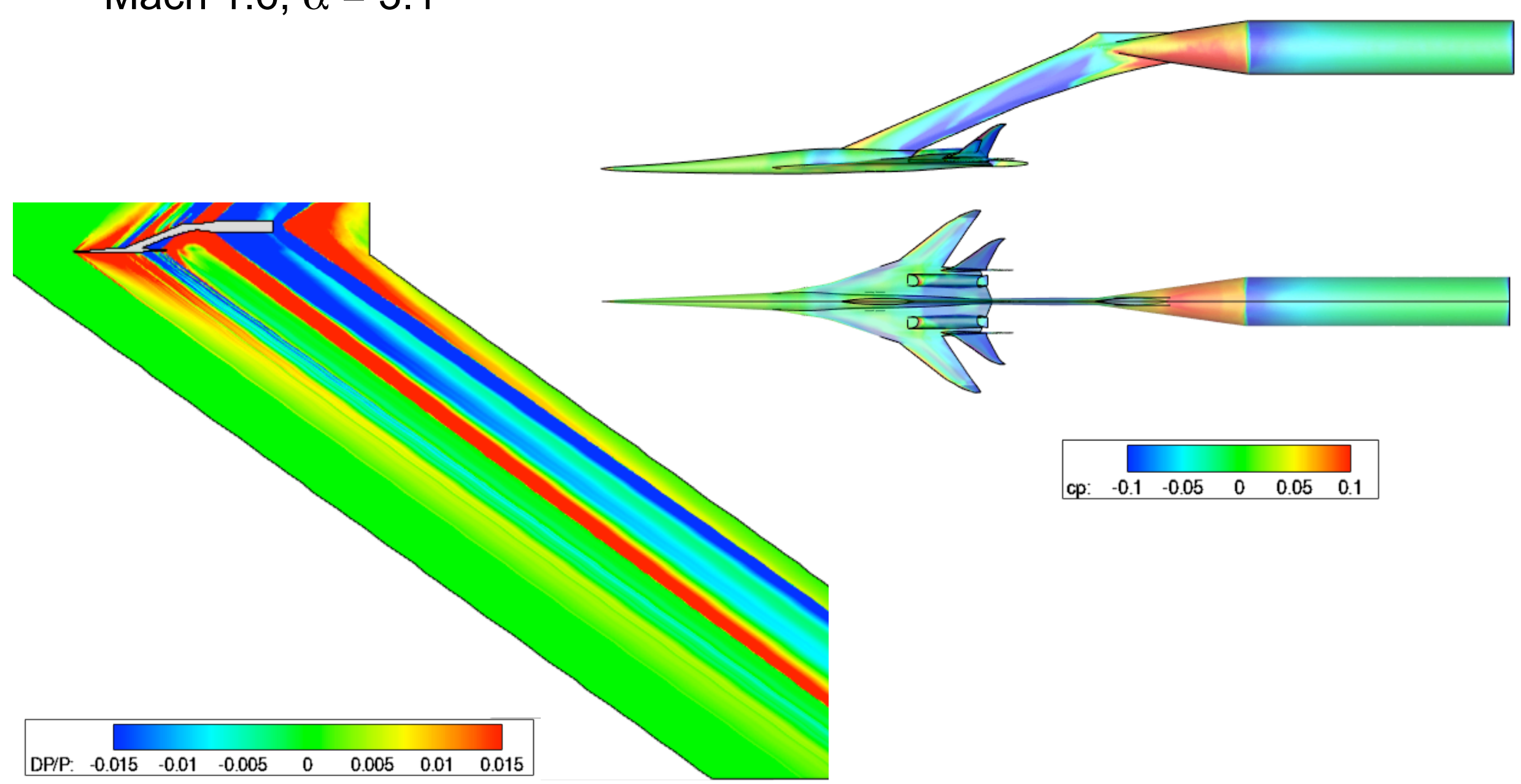


\section{Boom3 VS3 Experiment / CFD Comparisons at Various Off-Track Angles}

- Best exp./CFD agreement at $15^{\circ}$ off-track angle, though all predictions capture front ramp and main expansion fairly well

- Nose shock strength overpredicted by USM3D at $\phi=0^{\circ}$, but this diminishes to no shock by $\phi=45^{\circ}$, even though experimental data still show it

- Experimental shocks somewhat washed out by spatial averaging, CFD tends to show more detail, especially at $\phi=0^{\circ}$

- Issues with experimental \& CFD data are still being investigated...

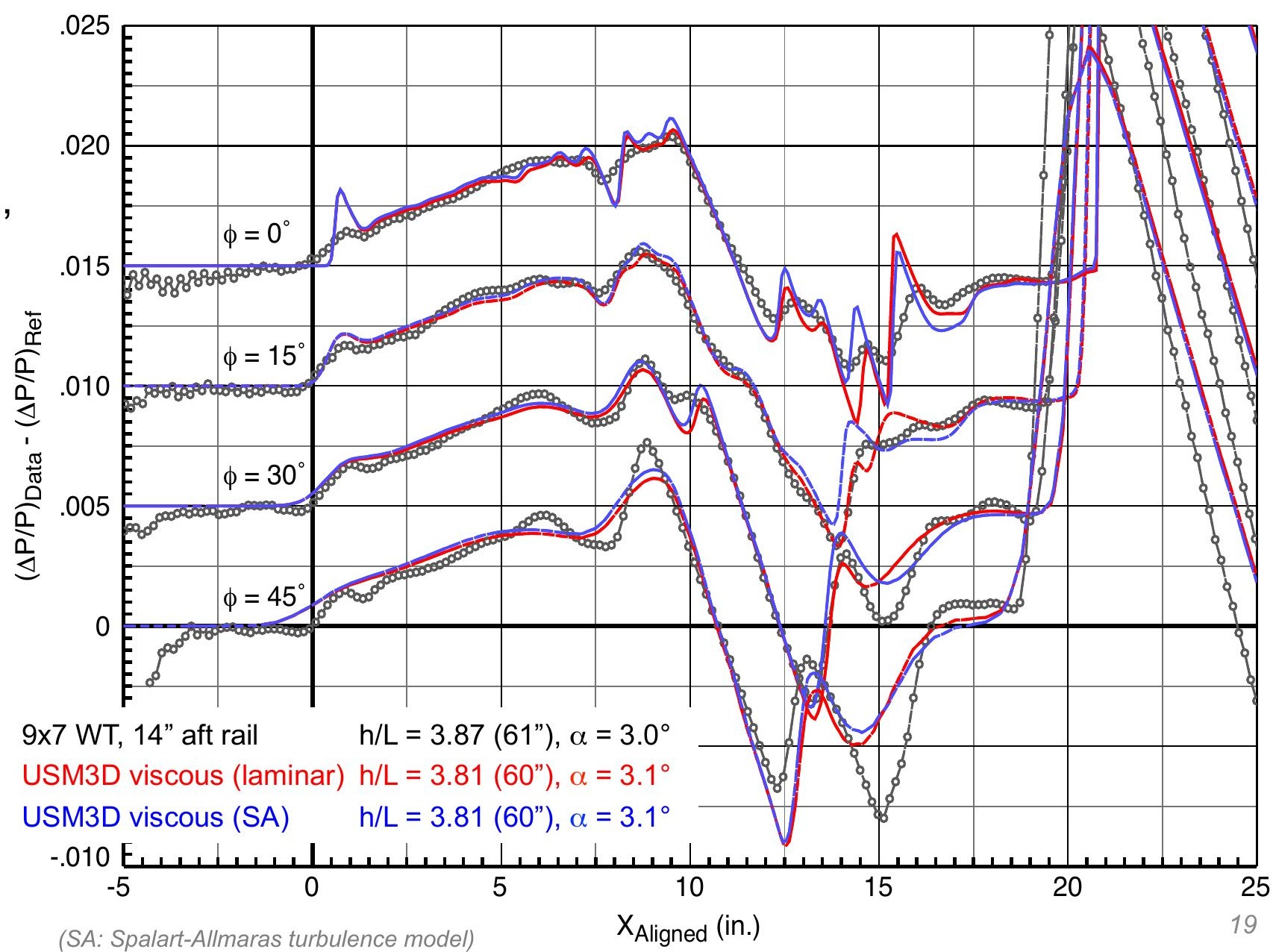




\section{Performance Model Surface Pressure Contours}

- Surface pressures and symmetry plane flow field pressures computed by USM3D with SA turbulent model

- Mach 1.6, $\alpha=3.4^{\circ}$

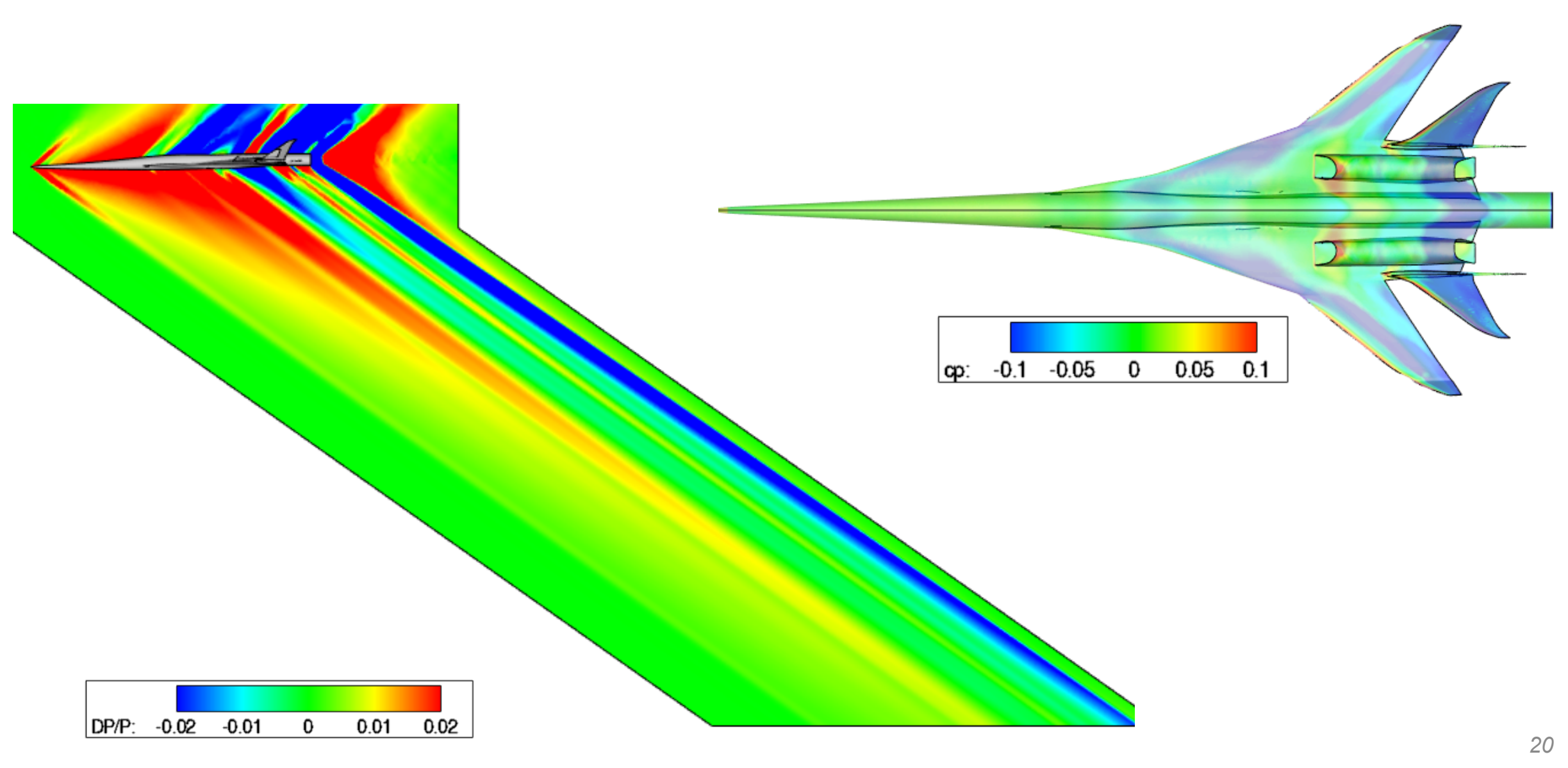


Performance Model

Experiment / CFD

Comparisons at Various Off-Track Angles

- Exp.: Performance model with tailored dummy sting

CFD: Performance model with sting can

- Shocks after main expansion not expected to match

- CFD captures general trends of front ramp and main expansion, but exp. data have many more small shocks

- These small shocks not seen in Boom model data

- Forebody contours on Performance model are smooth, not sure what is causing the shocks

- Issues with experimental \& CFD data are still being investigated...

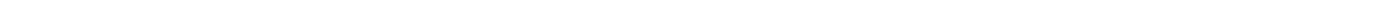




\section{Performance Model Sting Options}

- Model originally run with sting can

- Extends circular shape of aft body about 6"

- Has cavity and aft-facing step down to sting diameter

- Tailored dummy sting (covers) made during Phase II

- Used in place of sting can

- Continues aft-body shape about 17" behind model

- Intended to move effect of cross-section change further aft for cleaner aft signature

- Only for boom signatures, not force data since balance is "fouled"

SPLIT CAN

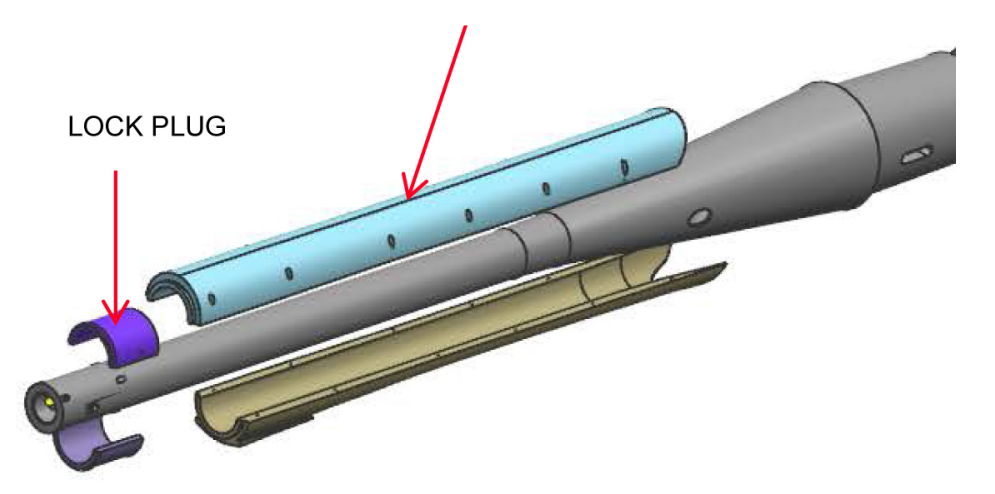




\section{Conclusions}

- Wind tunnel tests were conducted and CFD predictions were made in support of $\mathrm{N}+2 \mathrm{NRA}$ studies

- Spatial-averaging test technique yielded good repeatability of model signatures-removed distortions due to different locations of models relative to rail

- 14-in. "RF1" rail data matched CFD fairly well, 2-in. rail data required correction for reflection factor

- Inviscid CFD flow solvers generally overpredicted shock strengths, inclusion of boundary layer effects in viscous solvers gave better results

- Validation of CFD predictions with test data in these $\mathrm{N}+2$ studies has significantly advanced the state of the art in low-boom aircraft design and test, and gives confidence in being able to design for low boom 
